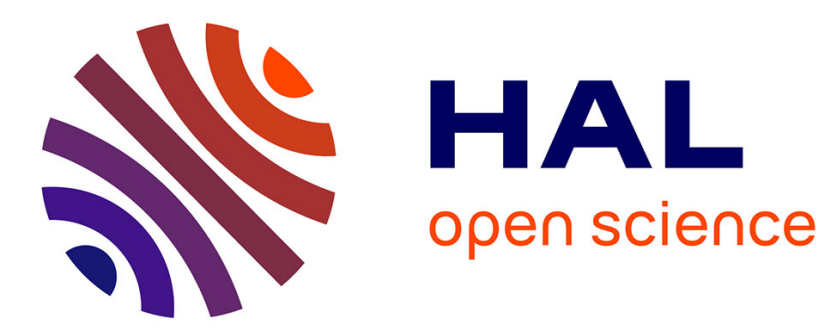

\title{
Of local translation control and lipid signaling in neurons
} Hervé Moine, Nicolas Vitale

\section{To cite this version:}

Hervé Moine, Nicolas Vitale. Of local translation control and lipid signaling in neurons. Advances in Biological Regulation, 2019, 71, pp.194-205. 10.1016/j.jbior.2018.09.005 . hal-02396044

\section{HAL Id: hal-02396044 https://hal.science/hal-02396044}

Submitted on 20 Dec 2021

HAL is a multi-disciplinary open access archive for the deposit and dissemination of scientific research documents, whether they are published or not. The documents may come from teaching and research institutions in France or abroad, or from public or private research centers.
L'archive ouverte pluridisciplinaire HAL, est destinée au dépôt et à la diffusion de documents scientifiques de niveau recherche, publiés ou non, émanant des établissements d'enseignement et de recherche français ou étrangers, des laboratoires publics ou privés.

\section{다)(1) $\$$}

Distributed under a Creative Commons Attribution - NonCommercial| 4.0 International 
Version of Record: https://www.sciencedirect.com/science/article/pii/S2212492618301362

Manuscript_acc30aaea45a7b093c4cb757bba5fc09

\section{Local climate zone approach on local and micro scales: dividing the urban open space}

A. Rodler $^{1,2}$, T. Leduc ${ }^{3}$

1 : Cerema, Equipe-Projet BPE, F-44000, Nantes, France

2 : AAU - CRENAU, Ecole Nationale Supérieure d'Architecture de Nantes, Nantes, France

3: AAU - CRENAU, CNRS, Nantes, France

Corresponding author :

Auline Rodler

Cerema Ouest : MAN - 9 rue René Viviani - CS 46223 - NANTES cedex 2

auline.rodler@cerema.fr 